\title{
Study on Front Axle of a Dump Truck with Assisted Electric Drive Based on HyperWorks
}

\author{
Zhixue Tong \& Yinan Lin \\ Mechanism and Electron College, Xi'an University of Architecture and Technology, Xi'an 710055, China
}

ABSTRACT: In view of the traditional rear wheel drive mining equipment has such problems as lack of climbing performance and skid in harsh environments, a front axle drive scheme is proposed. That increases the driving force of the overloading uphill and the braking force of the overloading downhill of the dump truck by adding a set of assisted electric drive system to the front axle. It may directly affect the use of the dump truck that the installed assisted electric drive system changing the forced condition and intensity of the front axle. So on the basis of 3d modeling, HyperWorks software has carried on to the finite element analysis to the typical working condition of the front axle. The research results show that the strength and deformation of the front axle are comply with the design requirements, and prove the rationality and security of the installed assisted electric drive system.

KEYWORD: Dump Truck; Front Axle; HyperWorks; Assisted Electric Drive; Finite Element Analysis; Inwheel Motor

\section{INTRODUCTION}

Traditional rear-axle-drive mining dumpers may encounter issues such as deficient climbing performance and tire slipping owing to wet road condition, steep ramp or other reasons (Z.S. Yu, 2000), which shall in turn greatly influence dumpers' working efficiency. The reason lies in the fact that dumpers will decrease adhesive force and braking performance in abominable conditions. Adding electronic auxiliary driving system to front axle can enhance vehicle's driving force while ascending with heavy loads, and simultaneously (W.X. Liu, 2001) (S.J. Guo et al, 2012), provide additional braking performance as descending with heavy loads, which shall finally improve working efficiency in the end (S. Zhu et al, 2007). Therefore, this thesis puts forward a set of front axle driving programs which add electronic auxiliary driving system to front axle (K. Zhao et al, 2015) (B. Meng et al, 2014). At the same time, in consideration of potential front axle's security issues triggered by force condition variation, this thesis further conducts an analytic research on intensity.

\section{ELECTRONIC AUXILIARY DRIVING SYSTEM DESIGN}

Traditional dumpers' front axle can only exert steering function, while rear axle exerts driving function through engines and mechanical transmission.
For maintaining original dumper's overall performance and structure and simultaneously adding front axle's electronic auxiliary driving force (Z.H. Kong et al, 2013) (W. Zhou, 2009) (L. Xiang, 2008), on the basis of original rear-axle mechanical driving structure, this thesis merely adds electronic auxiliary driving system to the front axle.

Remoulding hub internal structure by adding hub electrical machine for auxiliary driving while remaining original steering axle structure. Detailed structure is as shown in Fig. 1.
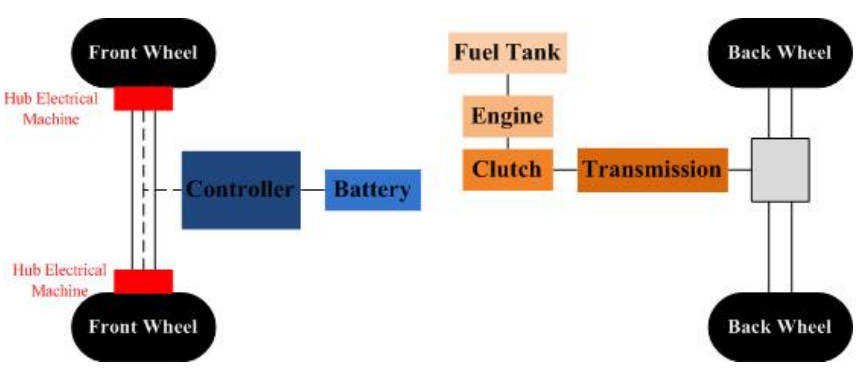

Fig.1 Drive Mode of Dump Truck with Assisted Electric Drive

This program has advantages over small torque in individual electrical machine, which means that electrical machine directly applied to hub can effectively shorten power transmission line to save space without changing front axle structure. Therefore, it has better control performance and power loss. 


\section{FRONT AXLE FINITE ELEMENT MODEL}

Owing to the auxiliary driving system added on front axle, front condition shall vary. Therefore, it is necessary to make an intensity analysis on front axle epipodium by reference to the design requirements of current front axle electronic auxiliary driving programs in order to ensure intensity requirements suitable for dumper operation.

This thesis adopts 3D modeling software Pro/E to make a front axle 3D modeling, and meanwhile simplifies micropore, circular bead, boss and other insignificant components. Consequently, finite element analysis software HyperWorks shall be utilized.

The material of front axle is $12 \mathrm{Mn} 2 \mathrm{VB}$ which has elasticity modulus of $\mathrm{E}=2.10 \times 10^{5} \mathrm{MPa}$, Poisson's ratio $\mu=0.3$ and yield limit $480 \mathrm{MPa}$. Relevant dumper parameters are as shown in Table 1.

Table1 Relevant parameters of front axle electronic auxiliary driving dumper

\begin{tabular}{ll}
\hline front wheel tread(mm) & 2640 \\
\hline rolling radius(mm) & 652 \\
\hline $\begin{array}{l}\text { Terrain clearance of plate spring seat upper surface } \\
(\mathrm{mm})\end{array}$ & 560 \\
\hline front axle loading( $\mathrm{kg})$ & 13440 \\
\hline mass center height under full load(mm) & 2255 \\
\hline $\begin{array}{l}\text { Distance between centers of two plate spring seats } \\
\text { (mm) }\end{array}$ & 1180 \\
\hline wheel base of front axle and rear axle (mm) & 3800 \\
\hline Road friction coefficient & 0.5 \\
\hline Mass transfer coefficient of front axle as braking & 1.7 \\
\hline Mass transfer coefficient of front axle as steering & 0.6 \\
\hline Output torque of hub electrical machine(Nm) & 870 \\
\hline
\end{tabular}

Finally, this thesis shall adopt Solid Model and tetrahedron element to make mesh generation including 36318 nodes on entities after channeling front axle 3D modeling into HyperWorks. Finite Element Model is as shown in Fig.2.

\section{FRONT AXLE FORCE ANALYSIS AND STATIC ANALYSIS}

According to bibliography, front axle intensity analysis is mainly concentrated on analytical calculation of three dangerous operation occasions namely crossing uneven road occasion, braking occasion and sideslip occasion.

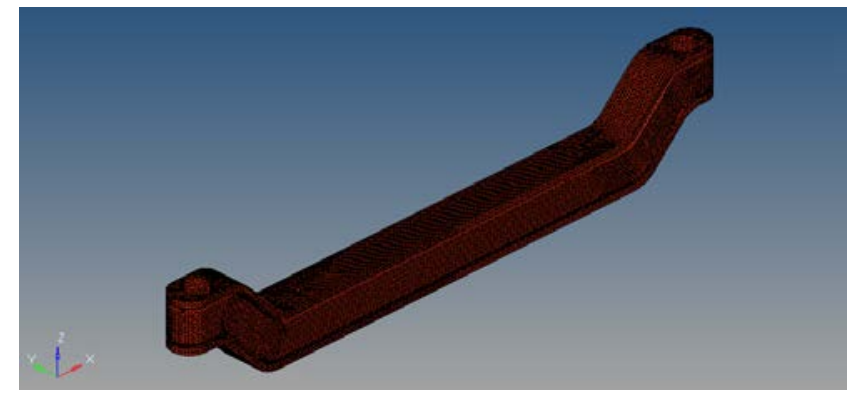

Fig.2 The Finite Element Model of the Front Axle

In addition, analytical calculation of front axle under maximum tractive force condition shall be conducted after adding electronic auxiliary driving system. Therefore, this thesis makes a finite element analysis of front axle according to above four conditions. Based on force analysis of dumper steering, crossing uneven road occasion is an occasion under individual vertical force, braking occasion is a combination occasion under vertical force and braking force, sideslip occasion is a combination occasion under vertical force and lateral force, and maximum tractive force condition is a combination occasion under vertical force and traction pull.

When loading the model, normal load shall be added to the lower surface of front axle ends, while lateral load and longitudinal load shall be added to the internal surface of pinhole. At the same time, two plate spring seats shall obtain comprehensive restraints.

\subsection{Static Analysis of Crossing Uneven Road Condition}

Crossing uneven road occasion is an occasion under individual vertical force with a vertical reaction force of

$$
\mathrm{F}_{\mathrm{zl}}=\mathrm{F}_{\mathrm{zr}}=\mathrm{K}_{\mathrm{d}} \mathrm{G} / 2
$$

Thereinto, $F_{z l}$ and $F_{z r}$ refer to vertical reaction force of two wheels; $K_{d}$ refers to the dynamic load coefficient 2.5; while $G$ means front axle's vertical load.

Front axle's force nephogram and cloud picture under crossing uneven road occasion are as shown in Fig.3.

According to the analysis, front axle's maximum force under above occasion is $276 \mathrm{MPa}$ and maximum force node is in plate spring seat; simultaneously, maximum deformation $0.7 \mathrm{~mm}$ appears in the two ends of axle. 


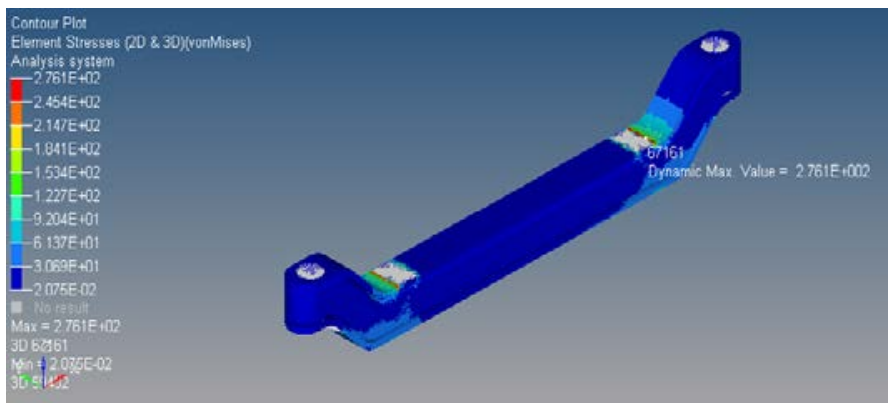

(a) Stress Figure

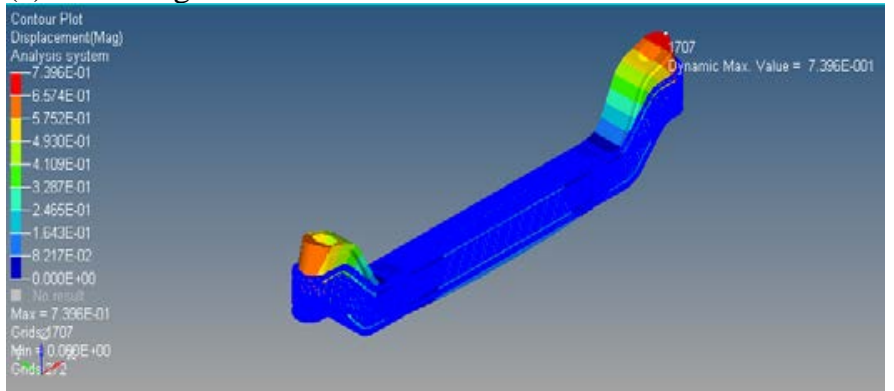

(b) Deformation Figure

Fig.3 The Stress Figure and Deformation Figure of Crossing the Rough Road

\subsection{Static Analysis of Braking Condition}

During emergency braking, two wheels shall suffer vertical reaction and braking force of surface with vertical reaction of

$$
\mathrm{F}_{\mathrm{zl}}=\mathrm{F}_{\mathrm{zr}}=\mathrm{m}_{1} \mathrm{G} / 2
$$

Thereinto, $\mathrm{F}_{\mathrm{zl}}$ and $\mathrm{F}_{\mathrm{zr}}$ mean the vertical reaction of wheels; $\mathrm{m} 1$ refers to front axle's mass transfer coefficient as braking, taking 1.7 as the value.

The maximum braking force is

$$
\mathrm{F}_{\mathrm{yl}}=\mathrm{F}_{\mathrm{yr}}=\mathrm{F}_{\mathrm{z}} \varphi
$$

There into, - - refers to maximum braking force of wheels; $F_{z}$ means vertical reaction of front wheels as braking; $\varphi$ means road friction coefficient of wheels.

Front axle's force nephogram and cloud picture as braking are as shown in Fig.4.

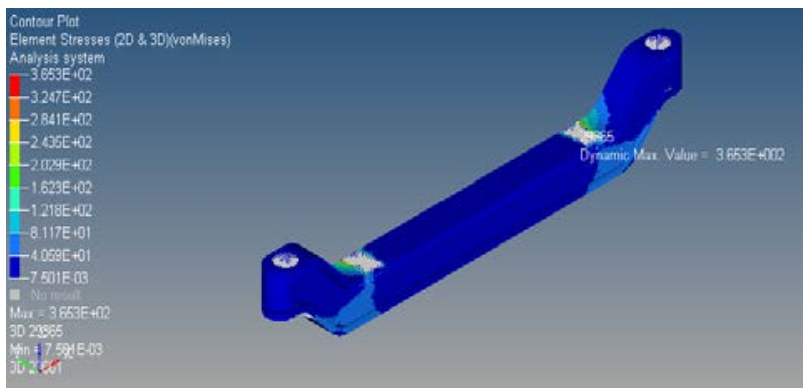

(a) Stress Figure

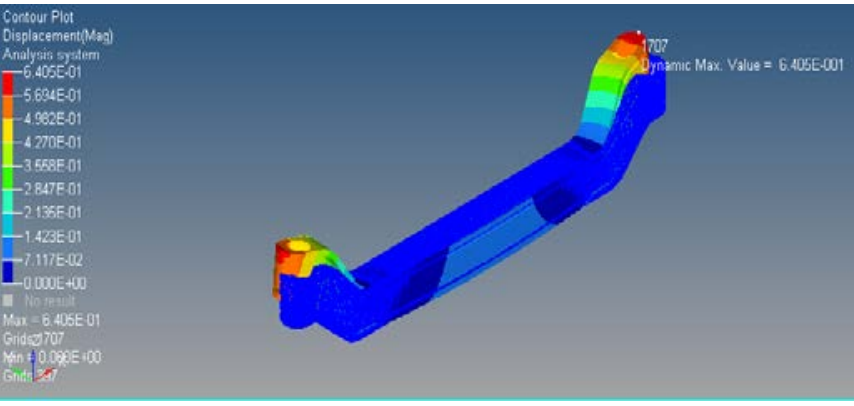

(b) Deformation Figure

Fig.4 The Stress Figure and Deformation Figure of the Braking

According to the analysis, front axle's maximum force under above occasion is $365 \mathrm{MPa}$ and maximum force node is in plate spring seat; simultaneously, maximum deformation $0.6 \mathrm{~mm}$ appears in the two ends of axle.

\subsection{Static Analysis of Sideslip Condition}

Sideslip occasion is a combination occasion under vertical load and lateral load, among which vertical reaction is

$$
\left\{\begin{array}{l}
F_{\mathrm{zl}}=\mathrm{G}\left(1 / 2-\mathrm{h}_{\mathrm{g}} \varphi / B\right) \\
\mathrm{F}_{\mathrm{zr}}=\mathrm{G}\left(1 / 2+\mathrm{h}_{\mathrm{g}} \varphi / B\right)
\end{array}\right.
$$

and lateral reaction

$$
\left\{\begin{array}{l}
\mathrm{F}_{\mathrm{xl}}=\varphi \mathrm{F}_{\mathrm{zl}} \\
\mathrm{F}_{\mathrm{xr}}=\varphi \mathrm{F}_{\mathrm{zr}}
\end{array}\right.
$$

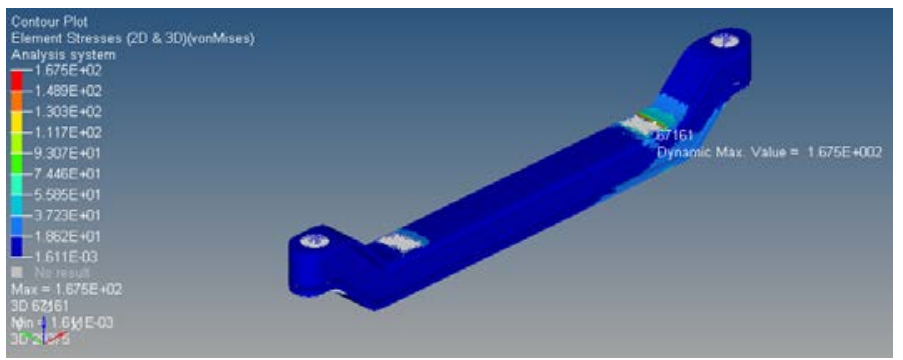

\section{(a) Stress Figure}

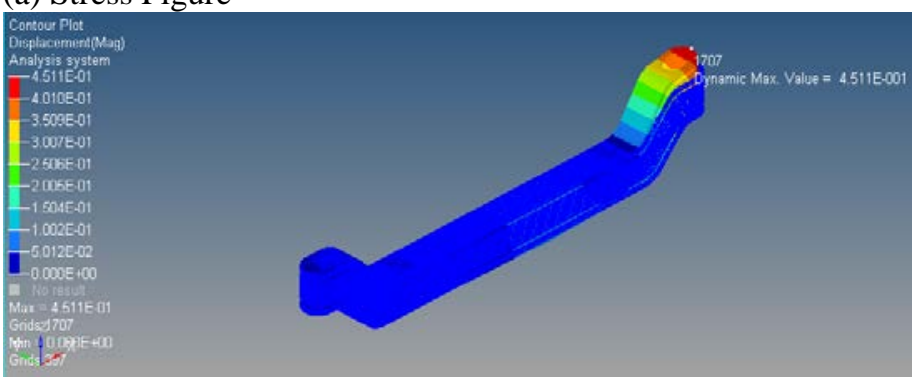

(b) Deformation Figure

Fig.5 The Stress Figure and Deformation Figure of the Side slipping

There into, $G$ refers to front axle's vertical load under full load; $h_{g}$ means mass center height under full load; B means front wheel tread; $\varphi$ means road friction coefficient which shall be 0.5 . 
Front axle's force nephogram and cloud picture in sideslip condition are as shown in Fig.5.

According to the analysis, front axle's maximum force under above occasion is $168 \mathrm{MPa}$ and maximum force node is on the right side of plate spring seat; simultaneously, maximum deformation $0.5 \mathrm{~mm}$ appears in the right side of axle end.

\subsection{Static Analysis of Maximum Tractive force}

Under maximum tractive force condition, two front wheels bear the combination forces of vertical reaction and hub electrical machine's maximum driving force, among which vertical reaction is

$$
\mathrm{F}_{\mathrm{zl}}=\mathrm{F}_{\mathrm{zr}}=\mathrm{m}_{2} \mathrm{G} / 2
$$

Thereinto, $\mathrm{F}_{\mathrm{z} 1}$ and $\mathrm{F}_{\mathrm{zr}}$ are vertical reaction of two wheels; $\mathrm{m}_{2}$ means front axle's mass transfer coefficient as steering which shall be 0.6.

Maximum driving force shall be

$$
\mathrm{F}_{\mathrm{yl}}=\mathrm{F}_{\mathrm{yr}}=\mathrm{M} / \mathrm{r}
$$

There into, $\mathrm{F}_{\mathrm{yl}}$ and $\mathrm{F}_{\mathrm{yr}}$ are maximum driving force of two wheels; $\mathrm{M}$ means the output torque of hub electrical machine; $r$ means front wheel's rolling radius.

Front axle's force nephogram and cloud picture under maximum tractive force occasion are as shown in Fig.6.

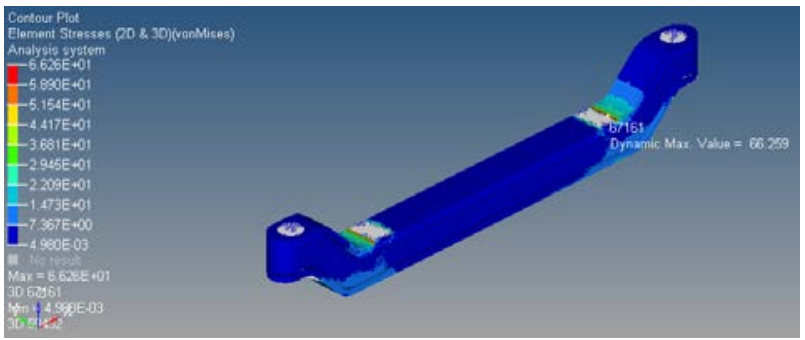

(a) Stress Figure

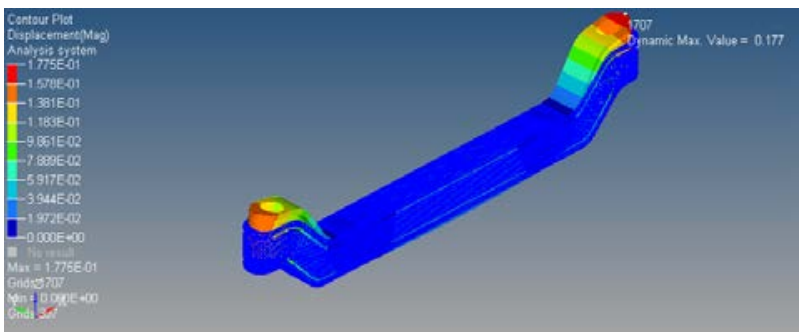

(b) Deformation Figure

Fig.6 The Stress Figure and Deformation Figure of the Maximum Traction

According to the analysis, front axle's maximum force under maximum tractive force occasion is 66.2MPa and maximum force node is in plate spring seat; simultaneously, maximum deformation 0.177 $\mathrm{mm}$ appears in the two ends of axle.

\section{FRONT AXLE INTENSITY ANALYSIS CONSEQUENCES}

Analysis of above four conditions indicates that maximum deformation occurs under crossing uneven road occasion, and moreover, all maximum deformation values are in a safe state less than allowable value $1 \mathrm{~mm}$. Front axle's maximum stress occurs under braking condition in which maximum stress value is less than material allowable stress. Therefore, front axle stress in static analysis is satisfactory with intensity security coefficient being 1.3 . In conclusion, dumper front axle is safe after adding electronic auxiliary driving system, which proves the rationality of electronic auxiliary driving system design.

\section{CONCLUSION}

This thesis designs dumper front axle electronic auxiliary driving program to increase dumper's driving force and therefore elevating its ascending performance. Decrease of sideslip risks effectively improves dumper's working efficiency under wet road and steep ramp conditions. In the meanwhile, front axle intensity also satisfies security requirements with obvious practical meaning and application value.

\section{REFERENCES}

B. Meng, B. Yao and Y. Yan: Automobile Applied Technology, Vol. 56(2014) No.10, p. 58.

K. Zhao, Y.S. Zeng and J.Z. Niu: Mechanical Engineer and Automation, Vol. 58 (2015) No.2, p.53.

L. Xiang: Finite element analysis about front axle vehicle of steady and dynamical performances (MS., Guangxi University. China 2008), p.18.

S.J. Guo and X. Luo: Auto Engineer, Vol. 20 (2012) No.6, p.33.

S. Zhu and L.J. Qian: Mechanical Research and Application, Vol. 31 (2007) No.2, p.44.

W.X. Liu: Automobile Design (Tsinghua University Press, China 2001)

W. Zhou: Finite Element Analysis on Portal Axle of Super-Low Floor City Bus (MS., Chang' a University. China 2009), p.31.

Z.H. Kong, L.M. Wang, R.S. Rong, G.L. Wang and H.L. Song: Machinery Design and Manufacture, Vol. 44 (2013) No.2, p.97.

Z.S. Yu: Automobile Theory (China Machine Press, China 2000) 